\title{
Silica, Silicosis, and Autoimmunity
}

\author{
Kenneth Michael Pollard* \\ Department of Molecular and Experimental Medicine, The Scripps Research Institute, La Jolla, CA, USA
}

Inhalation of dust containing crystalline silica is associated with a number of acute and chronic diseases including systemic autoimmune diseases. Evidence for the link with autoimmune disease comes from epidemiological studies linking occupational exposure to crystalline silica dust with the systemic autoimmune diseases systemic lupus erythematosus, systemic sclerosis, and rheumatoid arthritis. Although little is known regarding the mechanism by which silica exposure leads to systemic autoimmune disease, there is a voluminous literature on silica exposure and silicosis that may help identify immune processes that precede development of autoimmunity. The pathophysiology of silicosis consists of deposition of silica particles in the alveoli of the lung. Ingestion of these particles by macrophages initiates an inflammatory response, which stimulates fibroblasts to proliferate and produce collagen. Silica particles are encased by collagen leading to fibrosis and the nodular lesions characteristic of the disease. The steps in the development of silicosis, including acute and chronic inflammation and fibrosis, have different molecular and cellular requirements, suggesting that silica-induced inflammation and fibrosis may be mechanistically separate. Significantly, it is unclear whether silica-induced inflammation and fibrosis contribute similarly to the development of autoimmunity. Nonetheless, the findings from human and animal model studies are consistent with an autoimmune pathogenesis that begins with activation of the innate immune system leading to proinflammatory cytokine production, pulmonary inflammation leading to activation of adaptive immunity, breaking of tolerance, and autoantibodies and tissue damage. The variable frequency of these immunological features following silica exposure suggests substantial genetic involvement and gene/environment interaction in silica-induced autoimmunity. However, numerous questions remain unanswered.

Keywords: silica, silicosis, autoimmunity, human, animal model

\section{INTRODUCTION}

Environmental factors play a significant role in the development of human autoimmunity (1). These factors include the food we eat, the fluids we drink, the air we breathe, chemicals (natural and synthetic), infections, by-products of manufacturing processes, and radiation (2-4). A recent review of the epidemiologic evidence of environmental factors in human autoimmune diseases concluded that exposure to crystalline silica contributes to the development of a number of autoimmune diseases, including systemic lupus erythematosus (SLE), rheumatoid arthritis (RA), systemic sclerosis (SSc), and antineutrophil cytoplasmic antibody (ANCA)-related vasculitis (5). Despite this strong linkage of silica exposure with autoimmune diseases, there is little evidence of the possible mechanisms underlying this relationship $(6,7)$. This is due in large part to a lack of accepted criteria for diagnosis or classification of environmentally associated autoimmunity (8) as well as a 
paucity of animal models that mimic features of silica exposure in humans (6). In contrast, there is a voluminous literature on silica exposure and the development of silicosis in humans and animal models (9-11). In this article, I provide a brief overview of the immunological consequences of silica exposure and discuss how an understanding of identified mechanisms and biological markers may contribute to an understanding of silica-induced autoimmunity.

\section{SILICA AND INFLAMMATION}

Silica $\left(\mathrm{SiO}_{2}\right)$ is an oxide of silicon and is most commonly found in nature as quartz. Silica exists in many crystalline forms (called polymorphs) with $\alpha$-quartz being the most common form (11). Exposure to respirable crystalline silica $(<10 \mu \mathrm{m}$ in size) occurs most often in occupational settings, where materials containing crystalline silica are reduced to dust or when fine particles are disturbed. These occupations are often called the dusty trades and include abrasive blasting with sand, jack hammering, drilling, mining/tunneling operations, and cutting and sawing $(10,12)$. Inhaling crystalline silica dust can lead to silicosis, bronchitis, or cancer $(10,11)$. Silicosis is characterized by chronic inflammation and scarring in the upper lobes of the lungs and can be classified based on the quantity inhaled, time course, and length of exposure $(10,11,13)$. Chronic simple silicosis is the most common form, occurring after 15-20 years of moderate to low exposures to respirable crystalline silica. The accelerated form occurs after 5-10 years of high exposures to respirable crystalline silica, and acute silicosis, or silicoproteinosis, occurs after a few months or as long as 5 years following exposures to extremely high concentrations of respirable crystalline silica. The acute form is the most severe form of silicosis. The pathophysiology of silicosis involves deposition of particles into alveoli where they cannot be cleared. Ingestion of these particles by alveolar macrophages initiates an inflammatory response, which stimulates fibroblasts to proliferate and produce collagen. The silica particles are enveloped by collagen leading to fibrosis and nodular lesions characteristic of the disease.

\section{CELL AND MOLECULAR REQUIREMENTS FOR SILICA-INDUCED INFLAMMATION/ FIBROSIS}

A number of studies in experimental animals have revealed differences in silica-induced inflammatory responses and silicosis (14-16), arguing that gene-environment interactions are important in the severity of disease. Gene deletion studies have identified a number of the cellular and molecular requirements for silicainduced inflammation and fibrosis. The inflammatory response following exposure to crystalline silica is mediated by NALP3 inflammasome-driven IL-1 $\beta$ (17). Inflammasome activation is argued to occur following uptake of silica by scavenger receptors, lysosomal rupture, and release of cathepsin B accompanied by production of reactive oxygen species (ROS) and potassium efflux (10, 17-19) (Figure 1). The binding of silica to scavenger receptors also results in apoptosis of macrophages and the release of mediators (e.g., proinflammatory cytokines) contributing to lung inflammation and fibrosis (20). However, scavenger receptors also play a significant role in clearing silica, and their absence enhances inflammation but not fibrosis $(21,22)$.

Consistent with the differential requirements for scavenger receptors, the steps in the development of silicosis, including acute and chronic inflammation and fibrosis, have different molecular and cellular requirements (Figure 2). Inflammation and fibrosis occur independently of T, B, NKT, and NK cells (23), although treatment with anti-CD4 antibodies reduces the severity of fibrosis (24). This may be explained by the presumptive role of T regulatory cells in fibrosis (25). Deficiency of IL- $1 \alpha$ reduced IL- $1 \beta$ production and neutrophil accumulation following silica exposure (26), suggesting that release of endogenous IL- $1 \alpha$ from alveolar macrophages promotes subsequent lung inflammation. Pulmonary inflammation is also dependent on IFN- $\gamma$ (27), but not IL-4 or IL-13 (28) or IL-12 (29). In keeping with its antiinflammatory potential, IL-10 helps limit the silica-induced inflammatory response but amplifies the fibrotic response (30). The role of IL-10 in fibrosis appears to be due to exacerbation of the Th2 response and the production of profibrotic IL-4 and IL-13 (31). Acute inflammation, but not chronic inflammation or fibrosis, requires IL-17 (32), conversely, chronic inflammation, but not acute inflammation or fibrosis, requires type I IFN and IRF7 (33). Additional studies have suggested that presence of innate immune response components (particularly IL-1 receptor, IL-1, ASC, NALP3, IL-18 receptor, IL-33 receptor, TRIF, and TLR2, 3, and 4) are not required for accumulation of collagen in the lung (fibrosis), while inflammation, neutrophil accumulation, IL-1 $\beta$ release, and granuloma formation did require MyD88 (25). In contrast, others have suggested that absence of NALP3 and ASC reduces collagen deposition (17). While these studies may question the role of innate immunity in fibrosis, it is becoming clear that silica-induced inflammation and fibrosis can be uncoupled as evidenced by the observation that steroid treatment reduced lung inflammation and proinflammatory cytokine expression (TNF- $\alpha$, IL-1 $\beta$ ) but had no significant effect on lung fibrosis or expression of fibrogenic cytokines (TGF- $\beta$ and IL-10) (34).

\section{PROPERTIES OF SILICA THAT INFLUENCE INFLAMMATION}

Both amorphous (non-crystalline) silica particles and crystalline silica are phagocytosed by, and toxic to, macrophages leading to endolysosomal rupture and caspase-3 activation (35). Nevertheless, the size of silica particles can dramatically affect the inflammatory response. Amorphous silica particles of $30-1,000 \mathrm{~nm}$ in diameter induce greater inflammatory responses, as judged by lysosomal destabilization, proinflammatory cytokine expression, and pulmonary inflammation, than 3,000-10,000 $\mathrm{nm}$ particles (36). However, it is unclear if silica-induced lysosome destabilization is essential to NLRP3 inflammasome activation, IL- $1 \beta$ production, and inflammation. The binding of immobilized silica crystals to the cell membrane of macrophages was sufficient to induce IL- $1 \beta$ without evidence 

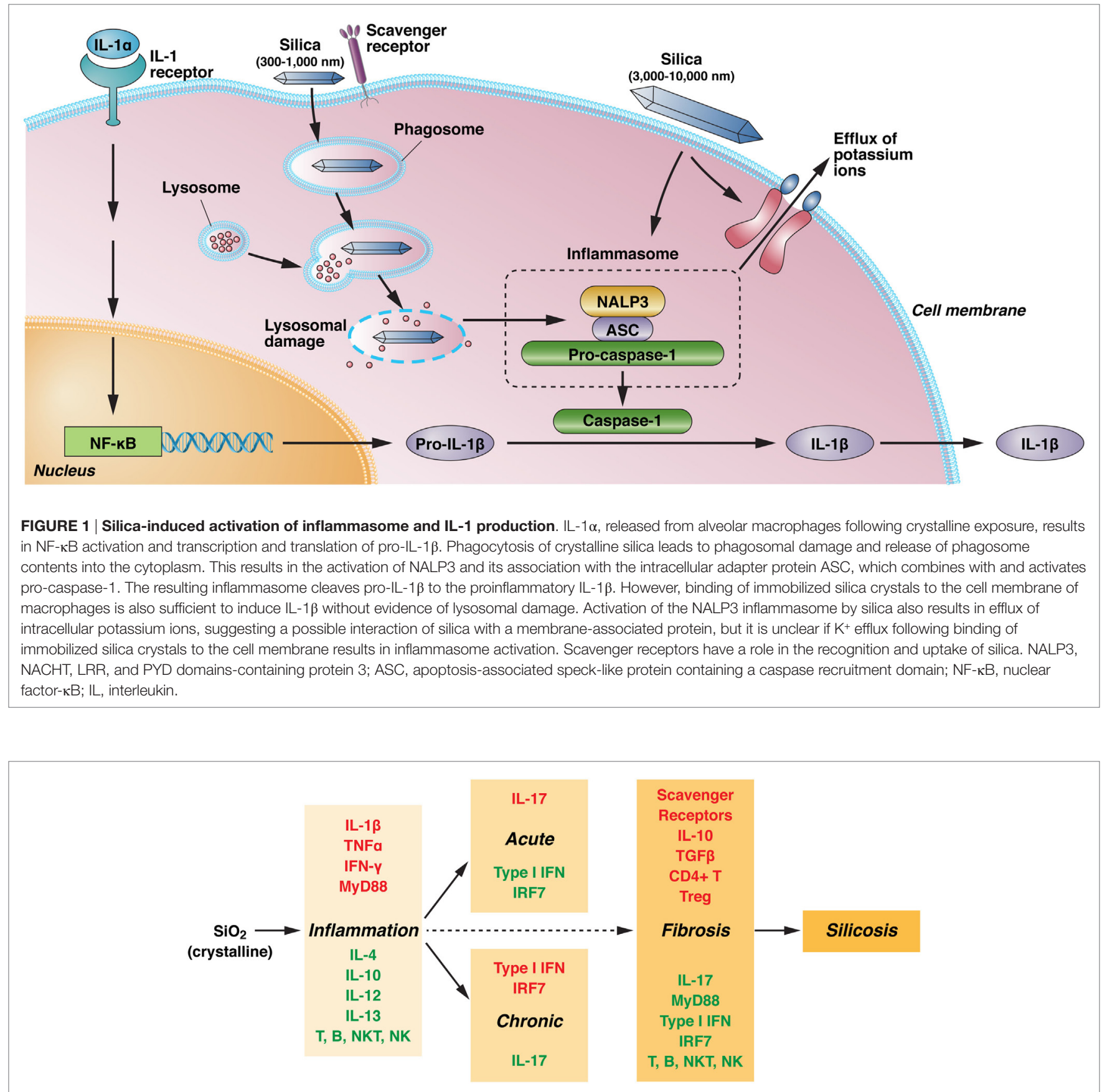

FIGURE 2 | Molecular and cellular components involved in silica-induced inflammation and fibrosis. Silicosis is marked by inflammation and fibrosis with the formation of nodular lesions in the upper lobes of the lungs. The collagen containing silicotic nodules are a specific response to crystalline silica. However, the cellular and molecular components responsible for the inflammatory and fibrotic responses are not the same. Components required for inflammation (acute or chronic) and fibrosis are highlighted in red, while those not essential have been highlighted in green (see text for details). TNF, tumor necrosis factor; IFN, interferon; MyD88, myeloid differentiation primary response gene 88; IL, interleukin; NK, natural killer; NKT, natural killer T cell; IRF, interferon regulatory factor; TGF,

transforming growth factor.

of lysosomal damage or a requirement for cathepsin B (18) (Figure 1). Blocking $\mathrm{K}^{+}$efflux from the cell was sufficient to reduce IL- $1 \beta$ release although whether potassium efflux is directly responsible for NLRP3 activation remains unclear (18). An alternative explanation for silica-induced IL-1 $\beta$ expression argues that silica exposure results in release of IL- $1 \alpha$ into the alveolar space, which then drives production of IL- $1 \beta$ and lung inflammation (26). This explanation is consistent with the concept that IL-1 $\alpha$ functions as an alarm molecule and plays a critical role early in inflammation (37). 


\section{SILICA-ASSOCIATED AUTOIMMUNITY}

A number of epidemiological studies support the association between occupational exposure to respirable crystalline silica dust and development of systemic autoimmune diseases $(5,12)$. Exposure to asbestos, another silicate that occurs in mining and construction, may be concurrent with crystalline silica exposure. While it can be difficult to assess the role of each separately, epidemiological data are too limited to argue for a strong association between asbestos exposure and autoimmunity (5). However, there is growing evidence that asbestos exposure may be associated with autoimmunity (e.g., hypergammaglobulinemia and autoantibodies) in the absence of confirmed autoimmune disease $(38,39)$. This is an important observation as several studies of crystalline silica exposure also point to the appearance of features of autoimmunity, especially autoantibodies, in exposed individuals in the absence of autoimmune disease $(40,41)$. This suggests that study of larger cohorts of asbestos exposed individuals may lead to stronger associations with autoimmune diseases.

For respirable crystalline silica dust, the prevalence of disease is increased when compared to the general population and shows evidence of strong occupational bias mostly associated with males (41). In high-level exposure, SLE is 10 times higher than the expected sex-specific prevalence in the general population $(12,41)$, but the strength of this association falls in both men and women as exposure is reduced (42). Moreover, there is evidence that disease features may differ between those with silica-induced systemic autoimmune disease and those with idiopathic disease $(41,42)$. Uranium miners with SLE had considerably less arthritis and also less photosensitivity compared to those with idiopathic SLE (41); there was also reduced prevalence of discoid lesions although this did not reach statistical significance. However, the silica group was all males with late onset disease, while the idiopathic disease group was $90 \%$ females and matched only for geographical location and ethnicity. Thus, it is unclear if the differences reflect silica exposure or sex and/or age differences. In the second study, demographic characteristics were more carefully controlled; however, the silica-exposed SLE patients were found to have reduced prevalence of anemia and leukopenia (42). Differences in autoantibodies have also been reported. Patients with silica-associated SSc had greater prevalence of anti-DNA topoisomerase 1 autoantibodies, and both silica-associated SSc and SLE had fewer patients with high titer antinuclear antibodies (ANA) $(>1: 1,280)$ compared to those with idiopathic disease (40).

Individual study populations have been found to have increased occurrence of different diseases suggesting a common underlying pathophysiology (43). This is supported by the observation that clinical features and autoantibodies specific to connective tissue diseases including anti-DNA, anti-SS-A/Ro, anti-SS-B/La, anticentromere, and anti-topoisomerase 1 occur at higher frequency in exposed individuals without autoimmune disease compared to the general population $(12,40,42)$. Although silicosis may be associated with immune abnormalities including autoantibodies, the association of silica exposure with expression of autoimmune disease can occur in the absence of silicosis $(12,41)$. Furthermore, while there is an association between intensity of exposure and autoantibodies including an association of high-level exposure with SLE, there is no relationship between autoantibodies and silicosis $(12,41,44)$. This suggests that the development of fibrosis and nodular lesions may not be required for development of autoimmunity. Whether this reflects the recent suggestion that fibrosis is linked to T regulatory cells (25) is uncertain.

The variable frequency of disease features in silica-induced autoimmunity suggests significant genetic involvement and gene/environment interactions. Silicosis can occur in $47-77 \%$ of individuals with adequate follow-up after silica exposure (45). In patients with silicosis, hypergammaglobulinemia can occur in over $65 \%$ of patients (46). In silicosis, ANA prevalence can be $34 \%$ or higher (47). End-stage renal disease due to silica exposure occurs in about $5 \%$ of exposed individuals (45), and development of diagnostically definable systemic autoimmune disease is even less frequent (12). These findings are consistent with a disease progression that begins with silica-induced activation of the innate immune system leading to inflammation of the lung, activation of adaptive immunity, breaking of tolerance, and autoantibodies and tissue damage.

\section{ANIMAL MODELING OF SILICA EXPOSURE TO MIMIC HUMAN AUTOIMMUNITY}

Only a small number of animal studies have modeled silicainduced autoimmunity. Lupus-prone NZM2410 mice exposed to crystalline silica exhibit pulmonary inflammation and fibrotic lesions, autoantibodies, kidney deposits of IgG and C3, proteinuria, and reduced survival compared to controls (48). A follow-up study reported increased TNF- $\alpha$ in bronchoalveolar lavage fluid (BALF), B1a B, and CD4 $4^{+} \mathrm{T}$ cells in lymph node as well as alteration in the ratio of $\mathrm{CD} 4^{+}$to $\mathrm{CD} 4^{+} \mathrm{CD} 25^{+} \mathrm{T}$ cells (49). A more recent study using lupus-prone NZBWF1 mice confirmed the exacerbation of SLE-like disease as well as identifying the formation of inducible bronchus-associated lymphoid tissue (iBALT) (50). Exposure to asbestos induces a similar spectrum of autoantibodies, kidney immune deposits, and changes in $\mathrm{CD} 4{ }^{+} \mathrm{CD} 25^{+}$ $\mathrm{T}$ cells in non-autoimmune prone C57BL/6 mice (51). Eronite, an asbestos-like fibrous mineral, induced ANA, IL-17, TNF- $\alpha$, and renal deposits of IgG in C57BL/6 mice (52). Asbestos exposure in Lewis rats failed to exacerbate arthritis induced by collagen or peptidoglycan-polysaccharide but did induce ANA, anti-histidyl tRNA synthetase antibodies, and proteinuria but showed no evidence of kidney immune deposits $(53,54)$. Nonautoimmune Brown Norway rats given sodium silicate $\left(\mathrm{NaSiO}_{4}\right)$ by subcutaneous injection developed ANA including anti-DNA, -Sm, -SS-A, and -SS-B (55). The ANA titers increased with time with the majority being positive for anti-RNP (56). These studies demonstrate that crystalline silica, and asbestos, can elicit autoimmunity in mice and rats and that non-crystalline silica can induce humoral autoimmunity in non-autoimmune prone rats, but they provide little evidence for possible mechanisms.

When mechanism has been examined, the results point to a significant role for cell death as a source of immune stimulation. ANA from crystalline silica-exposed NZM2410 mice 
preferentially bind to alveolar macrophage-like cells undergoing silica-induced apoptosis but not if apoptosis was inhibited by a caspase inhibitor (57), suggesting that silica-induced autoantibodies are directed against material from dying cells. This is supported by the observation that apoptosis induced by asbestos exposure results in surface blebs enriched in the autoantigen SSA/ Ro52, which are bound by autoantibodies from asbestos-exposed mice (58). Rottlerin, which affects kinase and non-kinase proteins as well as activating $\mathrm{K}^{+}$channels (59), reduced silica-induced proteinuria, autoantibodies, and IgG and C3 kidney deposits in lupus-prone NZM2410 mice (60). These studies led to the hypothesis that silica-induced activation of alveolar macrophages leads to apoptosis and inflammation, ingestion of cellular debris, migration of activated antigen-presenting cells (APCs) to lymph nodes, and activation of T and B cells (61). However, it is unclear how this leads to breaking of self-tolerance.

\section{CONCLUSION}

In aggregate, the immunological consequences of silica exposure that lead to autoimmunity are consistent with a disease progression that begins with activation of the innate immune system resulting in proinflammatory cytokine production, inflammation of the lung leading to activation of adaptive immunity, breaking of tolerance, and autoantibodies and renal damage. However, numerous questions remain unanswered.

It is unknown if the early events leading to IL- $1 \beta$ expression (Figure 1) are required for silica-induced autoimmunity. Are there size, shape, surface area, or charge rules for silica-induced lysosomal destabilization, $\mathrm{K}^{+}$efflux, and inflammasome activation? Does $\mathrm{K}^{+}$efflux play a role in silica-induced inflammation/ autoimmunity? The contribution of the inflammasome and IL-1 to systemic autoimmunity remains unclear (62) because while caspase 1 is required for pristane-induced autoimmunity (63), neither caspase 1 nor NALP3 is required for mercury-induced autoimmunity (64). Additional research is also needed to

\section{REFERENCES}

1. Pollard KM. Environment, autoantibodies, and autoimmunity. Front Immunol (2015) 6:60. doi:10.3389/fimmu.2015.00060

2. Jayapal M, Bhattacharjee RN, Melendez AJ, Hande MP. Environmental toxicogenomics: a post-genomic approach to analysing biological responses to environmental toxins. Int J Biochem Cell Biol (2010) 42:230-40. doi:10.1016/j. biocel.2009.10.007

3. Pollard KM. Gender differences in autoimmunity associated with exposure to environmental factors. J Autoimmun (2012) 38:J177-86. doi:10.1016/j. jaut.2011.11.007

4. Pollard KM, Kono DH. Requirements for innate immune pathways in environmentally induced autoimmunity. BMC Med (2013) 11:100. doi:10.1186/1741-7015-11-100

5. Miller FW, Alfredsson L, Costenbader KH, Kamen DL, Nelson LM, Norris JM, et al. Epidemiology of environmental exposures and human autoimmune diseases: findings from a National Institute of Environmental Health Sciences Expert Panel Workshop. JAutoimmun (2012) 39:259-71. doi:10.1016/j. jaut.2012.05.002

6. Germolec D, Kono DH, Pfau JC, Pollard KM. Animal models used to examine the role of the environment in the development of autoimmune disease: findings from an NIEHS Expert Panel Workshop. J Autoimmun (2012) 39:285-93. doi:10.1016/j.jaut.2012.05.020 determine if nanoparticles and other non-crystalline forms of silica lead to autoimmunity.

Many of the genetic requirements for silica-induced inflammation (Figure 2) are also required for systemic autoimmunity. In particular, IFN- $\alpha / \beta$ and/or IFN- $\gamma$ are required for idiopathic (65) and induced systemic autoimmunity $(66,67)$. Additionally, the role of IL-17 in autoimmunity continues to grow (68). Conversely, genetic elements required for silica-induced fibrosis may play little role in silica-induced autoimmunity. Deficiency of scavenger receptors exacerbates autoantibody responses (69). Moreover, the protective role of T regulatory cells and their cytokines IL-10 and TGF- $\beta$ in systemic autoimmunity $(70,71)$ argues that the fibrotic process elicited by silica exposure may negatively regulate the development of autoimmunity. It remains to be determined which of the molecular and cellular components that drive silicainduced inflammation and fibrosis explain the variable frequency of immunological features found in silica-induced autoimmunity.

Finally, a significant concern for future research is the paucity of animal models of silica-induced autoimmunity (6). Susceptibility to silicosis varies among inbred mouse strains (15) and no single inbred mouse strain mimics the genetic or disease heterogeneity found in humans. Considerable effort will be needed to identify an appropriate experimental model so that studies can be "shaped by what is observed in humans, not by what is possible in mice" (72).

\section{AUTHOR CONTRIBUTIONS}

The author confirms being the sole contributor of this work and approved it for publication.

\section{ACKNOWLEDGMENTS}

This work was supported by US National Institutes of Health (R01 ES021464, R01 ES022625, and R21 ES024485 to KP). The excellent technical assistance of Janet Hightower, BioMedical Graphics Department, for preparation of the figures is acknowledged.

7. Parks CG, Miller FW, Pollard KM, Selmi C, Germolec D, Joyce K, et al. Expert panel workshop consensus statement on the role of the environment in the development of autoimmune disease. Int J Mol Sci (2014) 15:14269-97. doi:10.3390/ijms150814269

8. Miller FW, Pollard KM, Parks CG, Germolec DR, Leung PS, Selmi C, et al. Criteria for environmentally associated autoimmune diseases. J Autoimmun (2012) 39:253-8. doi:10.1016/j.jaut.2012.05.001

9. Kawasaki H. A mechanistic review of silica-induced inhalation toxicity. Inhal Toxicol (2015) 27:363-77. doi:10.3109/08958378.2015.1066905

10. Leung CC, Yu IT, Chen W. Silicosis. Lancet (2012) 379:2008-18. doi:10.1016/ S0140-6736(12)60235-9

11. Mossman BT, Glenn RE. Bioreactivity of the crystalline silica polymorphs, quartz and cristobalite, and implications for occupational exposure limits (OELs). Crit Rev Toxicol (2013) 43:632-60. doi:10.3109/10408444.2013.818 617

12. Parks CG, Conrad K, Cooper GS. Occupational exposure to crystalline silica and autoimmune disease. Environ Health Perspect (1999) 107(Suppl 5):793-802. doi:10.1289/ehp.99107s5793

13. Castranova V, Vallyathan V. Silicosis and coal workers' pneumoconiosis Environ Health Perspect (2000) 108(Suppl 4):675-84. doi:10.2307/3454404

14. Callis AH, Sohnle PG, Mandel GS, Wiessner J, Mandel NS. Kinetics of inflammatory and fibrotic pulmonary changes in a murine model of silicosis. J Lab Clin Med (1985) 105:547-53. 
15. Davis GS, Leslie KO, Hemenway DR. Silicosis in mice: effects of dose, time, and genetic strain. J Environ Pathol Toxicol Oncol (1998) 17:81-97.

16. Ohtsuka Y, Wang XT, Saito J, Ishida T, Munakata M. Genetic linkage analysis of pulmonary fibrotic response to silica in mice. Eur Respir J (2006) 28:1013-9. doi:10.1183/09031936.06.00132505

17. Cassel SL, Eisenbarth SC, Iyer SS, Sadler JJ, Colegio OR, Tephly LA, et al. The Nalp3 inflammasome is essential for the development of silicosis. Proc Natl Acad Sci U S A (2008) 105:9035-40. doi:10.1073/pnas.0803933105

18. Hari A, Zhang Y, Tu Z, Detampel P, Stenner M, Ganguly A, et al. Activation of NLRP3 inflammasome by crystalline structures via cell surface contact. Sci Rep (2014) 4:7281. doi:10.1038/srep07281

19. Hornung V, Bauernfeind F, Halle A, Samstad EO, Kono H, Rock KL, et al. Silica crystals and aluminum salts activate the NALP3 inflammasome through phagosomal destabilization. Nat Immunol (2008) 9:847-56. doi:10.1038/ ni. 1631

20. Thakur SA, Hamilton RF Jr, Holian A. Role of scavenger receptor a family in lung inflammation from exposure to environmental particles. J Immunotoxicol (2008) 5:151-7. doi:10.1080/15476910802085863

21. Beamer CA, Holian A. Scavenger receptor class A type I/II (CD204) null mice fail to develop fibrosis following silica exposure. Am J Physiol Lung Cell Mol Physiol (2005) 289:L186-95. doi:10.1152/ajplung.00474.2004

22. Thakur SA, Beamer CA, Migliaccio CT, Holian A. Critical role of MARCO in crystalline silica-induced pulmonary inflammation. Toxicol Sci (2009) 108:462-71. doi:10.1093/toxsci/kfp011

23. Beamer CA, Migliaccio CT, Jessop F, Trapkus M, Yuan D, Holian A. Innate immune processes are sufficient for driving silicosis in mice. J Leukoc Biol (2010) 88:547-57. doi:10.1189/jlb.0210108

24. Barbarin V, Arras M, Misson P, Delos M, McGarry B, Phan SH, et al. Characterization of the effect of interleukin-10 on silica-induced lung fibrosis in mice. Am J Respir Cell Mol Biol (2004) 31:78-85. doi:10.1165/ rcmb.2003-0299OC

25. Re SL, Giordano G, Yakoub Y, Devosse R, Uwambayinema F, Couillin I, et al. Uncoupling between inflammatory and fibrotic responses to silica: evidence from MyD88 knockout mice. PLoS One (2014) 9:e99383. doi:10.1371/journal. pone. 0099383

26. Rabolli V, Badissi AA, Devosse R, Uwambayinema F, Yakoub Y, Palmai-Pallag $\mathrm{M}$, et al. The alarmin IL-1alpha is a master cytokine in acute lung inflammation induced by silica micro- and nanoparticles. Part Fibre Toxicol (2014) 11:69. doi:10.1186/s12989-014-0069-x

27. Davis GS, Holmes CE, Pfeiffer LM, Hemenway DR. Lymphocytes, lymphokines, and silicosis. JEnviron Pathol Toxicol Oncol (2001) 20(Suppl 1):53-65.

28. Misson P, Brombacher F, Delos M, Lison D, Huaux F. Type 2 immune response associated with silicosis is not instrumental in the development of the disease. Am J Physiol Lung Cell Mol Physiol (2007) 292:L107-13. doi:10.1152/ ajplung.00503.2005

29. Davis GS, Pfeiffer LM, Hemenway DR, Rincon M. Interleukin- 12 is not essential for silicosis in mice. Part Fibre Toxicol (2006) 3:2. doi:10.1186/1743-8977-3-2

30. Huaux F, Louahed J, Hudspith B, Meredith C, Delos M, Renauld JC, et al. Role of interleukin-10 in the lung response to silica in mice. Am J Respir Cell Mol Biol (1998) 18:51-9.

31. Barbarin V, Xing Z, Delos M, Lison D, Huaux F. Pulmonary overexpression of IL-10 augments lung fibrosis and Th2 responses induced by silica particles. Am J Physiol Lung Cell Mol Physiol (2005) 288:L841-8. doi:10.1152/ ajplung.00329.2004

32. Lo Re S, Dumoutier L, Couillin I, Van Vyve C, Yakoub Y, Uwambayinema F, et al. IL-17A-producing gammadelta $\mathrm{T}$ and Th17 lymphocytes mediate lung inflammation but not fibrosis in experimental silicosis. J Immunol (2010) 184:6367-77. doi:10.4049/jimmunol.0900459

33. Giordano G, van den Brule S, Lo Re S, Triqueneaux P, Uwambayinema F, Yakoub Y, et al. Type I interferon signaling contributes to chronic inflammation in a murine model of silicosis. Toxicol Sci (2010) 116:682-92. doi:10.1093/ toxsci/kfq158

34. Rabolli V, Lo Re S, Uwambayinema F, Yakoub Y, Lison D, Huaux F. Lung fibrosis induced by crystalline silica particles is uncoupled from lung inflammation in NMRI mice. Toxicol Lett (2011) 203:127-34. doi:10.1016/j. toxlet.2011.03.009
35. Costantini LM, Gilberti RM, Knecht DA. The phagocytosis and toxicity of amorphous silica. PLoS One (2011) 6:e14647. doi:10.1371/journal. pone. 0014647

36. Kusaka T, Nakayama M, Nakamura K, Ishimiya M, Furusawa E, Ogasawara K. Effect of silica particle size on macrophage inflammatory responses. PLoS One (2014) 9:e92634. doi:10.1371/journal.pone.0092634

37. Rider P, Carmi Y, Voronov E, Apte RN. Interleukin-1alpha. Semin Immunol (2013) 25:430-8. doi:10.1016/j.smim.2013.10.005

38. Pfau JC, Sentissi JJ, Weller G, Putnam EA. Assessment of autoimmune responses associated with asbestos exposure in Libby, Montana, USA. Environ Health Perspect (2005) 113:25-30. doi:10.1289/ehp.7431

39. Pfau JC, Serve KM, Noonan CW. Autoimmunity and asbestos exposure. Autoimmune Dis (2014) 2014:782045. doi:10.1155/2014/782045

40. Conrad K, Mehlhorn J. Diagnostic and prognostic relevance of autoantibodies in uranium miners. Int Arch Allergy Immunol (2000) 123:77-91. doi:10.1159/000024426

41. Conrad K, Mehlhorn J, Luthke K, Dorner T, Frank KH. Systemic lupus erythematosus after heavy exposure to quartz dust in uranium mines: clinical and serological characteristics. Lupus (1996) 5:62-9.

42. Parks CG, Cooper GS, Nylander-French LA, Sanderson WT, Dement JM, Cohen PL, et al. Occupational exposure to crystalline silica and risk of systemic lupus erythematosus: a population-based, case-control study in the southeastern United States. Arthritis Rheum (2002) 46:1840-50. doi:10.1002/ art. 10368

43. Sanchez-Roman J, Wichmann I, Salaberri J, Varela JM, Nunez-Roldan A. Multiple clinical and biological autoimmune manifestations in 50 workers after occupational exposure to silica. Ann Rheum Dis (1993) 52:534-8. doi:10.1136/ard.52.7.534

44. Conrad K, Stahnke G, Liedvogel B, Mehlhorn J, Barth J, Blasum C, et al. Anti-CENP-B response in sera of uranium miners exposed to quartz dust and patients with possible development of systemic sclerosis (scleroderma). J Rheumatol (1995) 22:1286-94.

45. Steenland K. One agent, many diseases: exposure-response data and comparative risks of different outcomes following silica exposure. Am J Ind Med (2005) 48:16-23. doi:10.1002/ajim.20181

46. Doll NJ, Stankus RP, Hughes J, Weill H, Gupta RC, Rodriguez M, et al. Immune complexes and autoantibodies in silicosis. JAllergy Clin Immunol (1981) 68:281-5. doi:10.1016/0091-6749(81)90152-4

47. Lippmann M, Eckert HL, Hahon N, Morgan WK. Circulating antinuclear and rheumatoid factors in coal miners. A prevalence study in Pennsylvania and West Virginia. Ann Intern Med (1973) 79:807-11. doi:10.7326/0003-4819-79-6-807

48. Brown JM, Archer AJ, Pfau JC, Holian A. Silica accelerated systemic autoimmune disease in lupus-prone New Zealand mixed mice. Clin Exp Immunol (2003) 131:415-21. doi:10.1046/j.1365-2249.2003.02094.x

49. Brown JM, Pfau JC, Holian A. Immunoglobulin and lymphocyte responses following silica exposure in New Zealand mixed mice. Inhal Toxicol (2004) 16:133-9. doi:10.1080/08958370490270936

50. Bates MA, Brandenberger C, Langohr I, Kumagai K, Harkema JR, Holian A, et al. Silica triggers inflammation and ectopic lymphoid neogenesis in the lungs in parallel with accelerated onset of systemic autoimmunity and glomerulonephritis in the lupus-prone NZBWF1 mouse. PLoS One (2015) 10:e0125481. doi:10.1371/journal.pone.0125481

51. Pfau JC, Sentissi JJ, Li S, Calderon-Garciduenas L, Brown JM, Blake DJ. Asbestos-induced autoimmunity in C57BL/6 mice. JImmunotoxicol (2008) 5:129-37. doi:10.1080/15476910802085756

52. Zebedeo CN, Davis C, Pena C, Ng KW, Pfau JC. Erionite induces production of autoantibodies and IL-17 in C57BL/6 mice. Toxicol Appl Pharmacol (2014) 275:257-64. doi:10.1016/j.taap.2014.01.018

53. Salazar KD, Copeland CB, Luebke RW. Effects of Libby amphibole asbestos exposure on two models of arthritis in the Lewis rat. J Toxicol Environ Health A (2013) 75:351-65. doi:10.1080/15287394.2012.668164

54. Salazar KD, Copeland CB, Wood CE, Schmid JE, Luebke RW. Evaluation of anti-nuclear antibodies and kidney pathology in Lewis rats following exposure to Libby amphibole asbestos. JImmunotoxicol (2013) 10:329-33. doi:10.3109/1547691X.2012.747230

55. Al-Mogairen SM, Al-Arfaj AS, Meo SA, Adam M, Al-Hammad A, Gad El Rab MO. Induction of autoimmunity in Brown Norway rats by oral 
and parenteral administration of sodium silicate. Lupus (2009) 18:413-7. doi:10.1177/0961203308098192

56. Al-Mogairen SM. Role of sodium silicate in induction of scleroderma-related autoantibodies in brown Norway rats through oral and subcutaneous administration. Rheumatol Int (2011) 31:611-5. doi:10.1007/s00296-009-1327-3

57. Pfau JC, Brown JM, Holian A. Silica-exposed mice generate autoantibodies to apoptotic cells. Toxicology (2004) 195:167-76. doi:10.1016/j.tox.2003. 09.011

58. Blake DJ, Wetzel SA, Pfau JC. Autoantibodies from mice exposed to Libby amphibole asbestos bind SSA/Ro52-enriched apoptotic blebs of murine macrophages. Toxicology (2008) 246:172-9. doi:10.1016/j.tox.2008.01.008

59. Soltoff SP. Rottlerin: an inappropriate and ineffective inhibitor of PKCdelta. Trends Pharmacol Sci (2007) 28:453-8. doi:10.1016/j.tips.2007.07.003

60. Brown JM, Schwanke CM, Pershouse MA, Pfau JC, Holian A. Effects of rottlerin on silica-exacerbated systemic autoimmune disease in New Zealand mixed mice. Am J Physiol Lung Cell Mol Physiol (2005) 289:L990-8. doi:10.1152/ajplung.00078.2005

61. Brown JM, Pfau JC, Pershouse MA, Holian A. Silica, apoptosis, and autoimmunity. J Immunotoxicol (2005) 1:177-87. doi:10.1080/15476910490911922

62. Pollard KM, Kono DH. Requirements for "Fire and ICE" differ between animal models of autoimmunity: comment on the article by Kahlenberg et al. Arthritis Rheumatol (2014) 66:2310-1. doi:10.1002/art.38678

63. Kahlenberg JM, Yalavarthi S, Zhao W, Hodgin JB, Reed TJ, Tsuji NM, et al. An essential role for caspase-1 in the induction of murine lupus and its associated vascular damage. Arthritis Rheum (2014) 66:152-62. doi:10.1002/art.38225

64. Pollard KM, Hultman P, Toomey CB, Cauvi DM, Hoffman HM, Hamel JC, et al. Definition of IFN-gamma-related pathways critical for chemically-induced systemic autoimmunity. J Autoimmun (2012) 39:323-31. doi:10.1016/j. jaut.2012.04.003

65. Baccala R, Kono DH, Theofilopoulos AN. Interferons as pathogenic effectors in autoimmunity. Immunol Rev (2005) 204:9-26. doi:10.1111/j.0105-2896.2005. 00252.x
66. Nacionales DC, Kelly KM, Lee PY, Zhuang H, Li Y, Weinstein JS, et al. Type I interferon production by tertiary lymphoid tissue developing in response to 2,6,10,14-tetramethyl-pentadecane (pristane). Am JPathol (2006) 168:1227-40. doi:10.2353/ajpath.2006.050125

67. Pollard KM, Cauvi DM, Toomey CB, Morris KV, Kono DH. Interferon-gamma and systemic autoimmunity. Discov Med (2013) 16:123-31.

68. Burkett PR, Meyer zu Horste G, Kuchroo VK. Pouring fuel on the fire: Th17 cells, the environment, and autoimmunity. J Clin Invest (2015) 125:2211-9. doi:10.1172/JCI78085

69. Wermeling F, Chen Y, Pikkarainen T, Scheynius A, Winqvist O, Izui S, et al. Class A scavenger receptors regulate tolerance against apoptotic cells, and autoantibodies against these receptors are predictive of systemic lupus. J Exp Med (2007) 204:2259-65. doi:10.1084/jem.20070600

70. Michels-van Amelsfort JM, Walter GJ, Taams LS. CD4+CD25+ regulatory $\mathrm{T}$ cells in systemic sclerosis and other rheumatic diseases. Expert Rev Clin Immunol (2011) 7:499-514. doi:10.1586/eci.11.28

71. Okamoto A, Fujio K, Okamura T, Yamamoto K. Regulatory T-cell-associated cytokines in systemic lupus erythematosus. J Biomed Biotechnol (2011) 2011:463412. doi:10.1155/2011/463412

72. von Herrath M, Nepom GT. Animal models of human type 1 diabetes. Nat Immunol (2009) 10:129-32. doi:10.1038/ni0209-129

Conflict of Interest Statement: The author declares that this manuscript and associated research was done in the absence of any commercial or financial relationships that could be construed as a potential conflict of interest.

Copyright $\odot 2016$ Pollard. This is an open-access article distributed under the terms of the Creative Commons Attribution License (CC BY). The use, distribution or reproduction in other forums is permitted, provided the original author(s) or licensor are credited and that the original publication in this journal is cited, in accordance with accepted academic practice. No use, distribution or reproduction is permitted which does not comply with these terms. 